\title{
PMSM Drive Position Estimation: Contribution to the High Frequency Injection Voltage Selection Issue
}

\author{
S. Medjmadj, D. Diallo, Senior Member IEEE, M. Mostefai, C. Delpha, Member IEEE, A. Arias
}

\begin{abstract}
High Frequency Injection (HFI) is an alternative method to estimating Permanent Magnet Synchronous Motor (PMSM) rotor position using magnetic saliency. Once the maximum fundamental electrical frequency and the power converter switching frequency are set, the HFI voltage amplitude tuning is generally based on trial and error. This paper proposes a methodology to select the appropriate high frequency signal injection voltage amplitude for rotor position estimation. The technique is based on an analytical model taking into account the noise in the voltage supply to derive the resulting currents containing the information on the rotor position. This model allows setting the injection voltage amplitude that leads to the maximum acceptable position error for a given Signal to Noise Ratio (SNR) and a speed range. The approach is validated with the analytical and the global drive models through extensive simulations. Experimental results on a $1.1 \mathrm{~kW}$ PMSM drive confirm the interest of the proposed solution.
\end{abstract}

Index Terms--AC motor drives, Rotor Position Estimation, Gaussian noise, Signal-to-noise ratio, Permanent Magnet Synchronous Motor (PMSM).

\section{NOMENCLATURE}

$\theta_{r}, \hat{\theta}_{r}$ : Actual and estimated rotor electric position (rad).

$\theta:$ Rotor mechanical position ( $\mathrm{rad}$ )

$L_{d}, L_{q}: \mathrm{d}$ and q-axis stator inductances respectively $(\mathrm{H})$.

$\mathrm{R}_{\mathrm{s}}$ : Stator resistance $(\Omega)$.

$\mathrm{V}_{\mathrm{a}}, \mathrm{V}_{\mathrm{b}}, \mathrm{V}_{\mathrm{c}}$ : Voltages in the $(a, b, c)$ reference frame $(\mathrm{V})$.

$V_{\alpha}, V_{\beta}, i_{\alpha}, i_{\beta}:$ Voltages and currents in the Clark $(\alpha, \beta)$ reference frame.

$V_{d}, V_{q}, i_{d}, i_{q}$ : Voltages and currents in the Park $(d, q)$ reference frame.

$\psi_{\alpha}, \psi_{\beta}$ : Fluxes in $(\alpha, \beta)$ frame $(\mathrm{Wb})$.

$\psi_{d}, \psi_{q}$ : Fluxes in $(d, q)$ frame $(\mathrm{Wb})$.

$\psi_{m}$ : Rotor flux due to the permanent magnets $(\mathrm{Wb})$

$w_{\mathrm{r}}$ : Electrical rotor speed $(\mathrm{rad} / \mathrm{s})$.

$\Omega, \hat{\Omega}:$ Actual and estimated rotor speed ( $\mathrm{rad} / \mathrm{s})$.

$\Omega_{\text {ref: }}$ Rotor speed reference ( $\left.\mathrm{rad} / \mathrm{s}\right)$.

$\rho$ : Derivative operator $\mathrm{d} / \mathrm{dt}$.

$\mathrm{f}_{\mathrm{i}}:$ Injection frequency $(\mathrm{Hz}), .(\mathrm{rad} / \mathrm{s}), \omega_{i}=2 \pi f_{i}$

$\mathrm{V}_{\mathrm{si}}$ : High frequency injected carrier voltage $(\mathrm{V})$.

$\mathrm{V}_{\mathrm{m}}$ : Maximum voltage amplitude $(\mathrm{V})$.

$\mathrm{n}_{1}, \mathrm{n}_{2}, \mathrm{n}_{3}$ : Additive noise amplitudes in $(a, b, c)$ reference frame $(V)$.

SNR : Signal-to-Noise Ratio (dB)

AWGN: Additive White Gaussian Noise

$\sigma^{2}$ : Variance

$\mu$ : Mean value.

PSD: Power Spectral Density.

$\varepsilon_{\theta}=\theta_{r}-\hat{\theta}_{r}:$ Rotor position error (rad).

$\varepsilon_{A M}:$ Rotor position error of the analytical model (rad).

$\varepsilon_{G M}:$ Rotor position error of the global model (rad).

S. Medjmadj is with the LAS, Univ. Bordj Bou Arreridj, Algeria,

\section{INTRODUCTION}

$\mathrm{P}$ MANENT magnet synchronous motors (PMSMs) have good performances such as, high energy density, fast dynamic response and good overload capacity. They are widely used in a variety of industrial applications, such as industrial robots, aeronautics, electric vehicle and machine tools [1-4]. In order to achieve high precision and fast dynamic control characteristics of PMSMs, an accurate rotor position measurement is necessary. This is usually done with a mechanical sensor, which will not only bring a cost increment but more importantly it might raise reliability issues due to the fact that such sensors are delicate and need additional electronics as well as extra cabling. Moreover, sensorless algorithms, even when using position sensors, are useful in case of any failures, as it may be used as a redundant sensor and therefore a fault tolerant control can be achieved. Therefore, there has been a high research activity focused on eliminating the position sensors mounted on the rotor of the PMSM machines to obtain the rotor position information indirectly [5-7].

In general there are three strategies. The first one is the knowledge-based (such as artificial intelligence, genetic algorithms, fuzzy logic, etc.) [8-10]. These methods suffer from the need of data recorded on the process to train the networks. The second one is physical-model based approach such as observers and estimators (MRAS, Luenberger, Extended Kalman Filter, Sliding Mode Observer, Differential Algebraic, etc.) [11-13].

These methods are mostly efficient for high speeds and have the disadvantages of heavy computation, especially when facing non sub-optimal Kalman Filters. They mainly suffer from the modeling errors or assumptions. For these reasons, significant research efforts have been conducted to develop alternative methods such as high frequency signal injection [14] as displayed in Fig.1.

(s medjmadj@yahoo.fr), D. Diallo is with the LGEP, CNRS UMR 8507, Supélec, Univ. Paris-Sud, Univ. Pierre et Marie Curie (ddiallo@ieee.org). M. Mostefai is with the LAS, Department of Electrical Engineering, Faculty of Technology, Univ. Ferhat Abbas, Setif, Algeria (mostefai@univ-setif.dz). C. Delpha is with the L2S, CNRS UMR 8506, Supélec, Univ. Paris Sud (claude.delpha@u-psud.fr), A. Arias is with the Univ. Politecnica de Catalyuna, Spain (antoni.arias@upc.edu). 


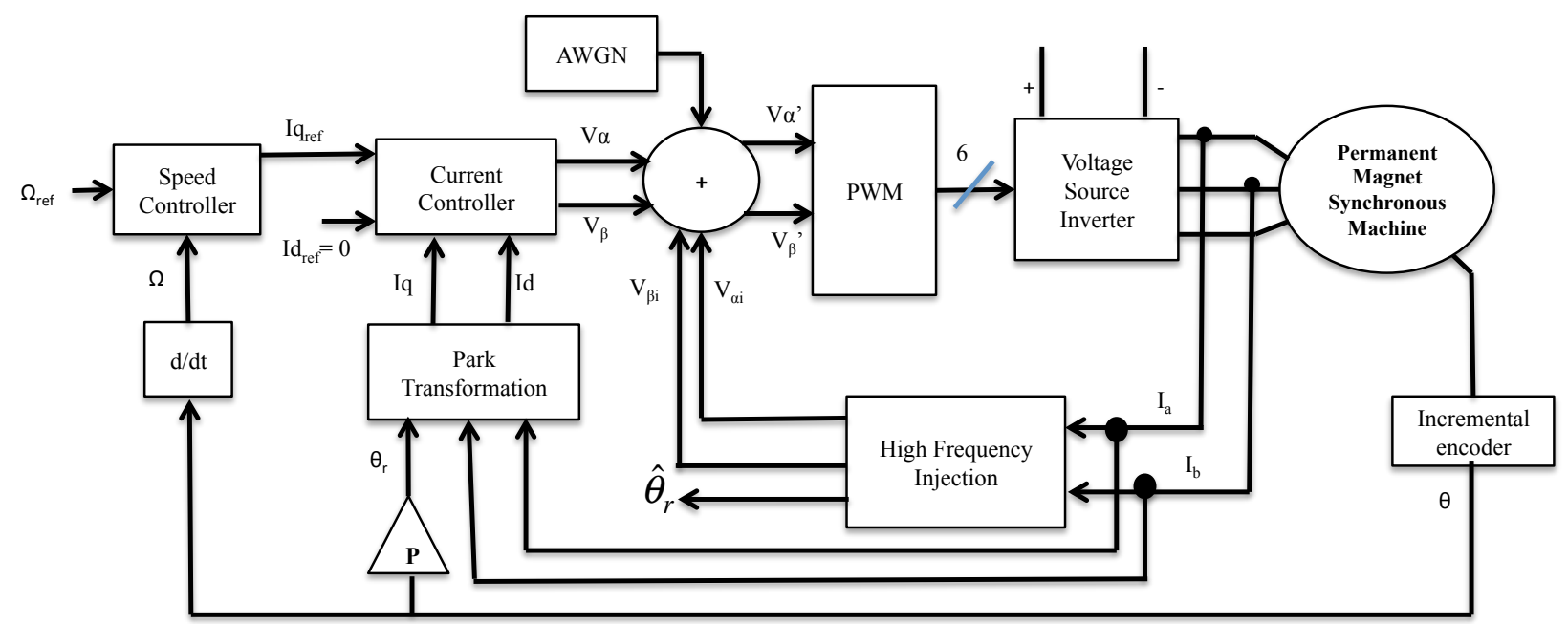

Fig.1. PMSM drive with high frequency voltage injection and noise addition

Even if it requires a PMSM with magnetic saliency, this approach seems promising particularly at low speed where the other methods usually fail

\section{HIGH FREQUENCY INJECTION AND PROBLEM STATEMENT}

\section{A. High frequency injection principle}

The technique consists in injecting either a pulse or a sinusoidal test signal in order to be able to track the existing magnetic saliency without introducing torque ripples.

The main issues are on the selection of the pulse shape, the frequency and the voltage amplitude. In the following, we focus on sinusoidal excitation. On one hand, the frequency is usually set in a range 10 times higher than the maximum fundamental frequency and 10 times lower than the power converter switching frequency. On the other hand, the voltage amplitude selection is somehow a random process. Too low voltage amplitude will not generate enough current and if the amplitude is too high, undesirable torque ripples will appear.

The injection of a rotating high frequency (HF) voltage for saliency tracking has been proposed by several authors [1517]. Several methods using analog filters and frequency shifts may be used to isolate the rotor position information. In [18], it is shown that the rotor position estimator for salient-pole PMSM is given by using only one low-pass filter. In our study, the position estimation is derived from a high frequency current injection by using three filters (a low-pass Filter (LPF) a high pass filter (HPF) and a band pass-filter (BPF), and the position estimation bias is cancelled thanks to a phase compensation scheme. A brief review of this process is displayed in Fig.2 [19-22].

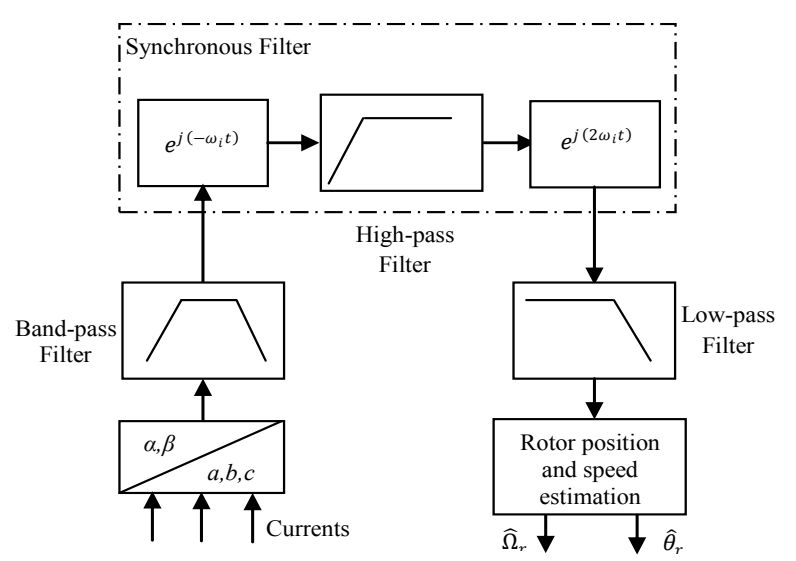

Fig.2. Synchronous filters for demodulation of HF currents.

\section{B. Noise Effect Analysis and paper's contribution}

Usually the HFI voltage amplitude is set by trial and tuned so as to have accurate position estimation after the demodulation. Our approach consists in determining with a theoretical approach how to set the minimum value of the HFI voltage amplitude that still guarantees good position estimation despite the noise level due to the inverter and the application environment.

This is done through an analytical model that will be presented in the paper. And to evaluate the noise effect with this theoretical approach, the AWGN is the most popular and usual noise model as it consists in adding a noise with a constant power all over the spectrum without emphasizing any particular frequency.

In the following, global model is denoted as the model including the PMSM, the field oriented control, the load, the high frequency injection and demodulation modules and the AWGN as displayed in figure 1 . 


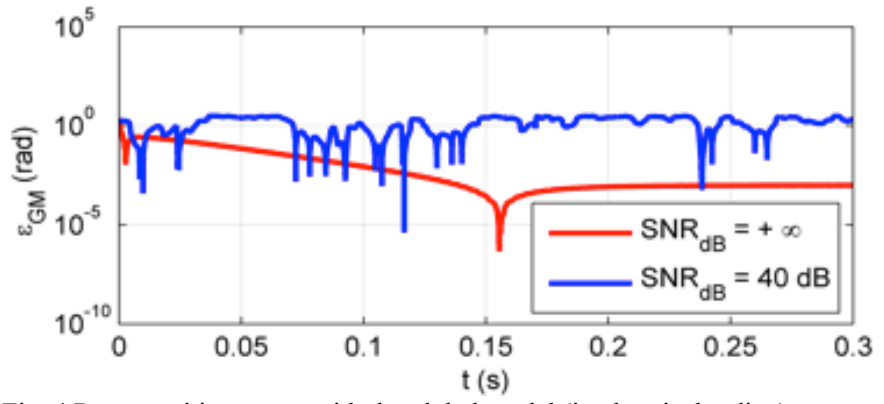

Fig. 4 Rotor position errors with the global model (in electrical radian)

It will be used as the reference to evaluate the analytical model developed in the following section. The environment is noisy due to the inverter switching and all the other perturbations [23-25]. This can be taken into account by considering the Signal to Noise Ratio $\left(\mathrm{SNR}_{\mathrm{dB}}\right)$ defined as:

$$
S N R_{d B}=10 \log _{10}\left(\frac{\sigma_{\text {signal }}^{2}}{\sigma_{\text {noise }}^{2}}\right)
$$

Where $\sigma^{2}$ is the variance. Both signal and noise power must be measured at the same or/and equivalent points in a system, and within the same system bandwidth.

To illustrate the noise effect on the studied system, a simulation of the PMSM drive has been done with an estimator based on high frequency injection (HFI). The comparison is made between an ideal case with a very high $\mathrm{SNR}_{\mathrm{dB}}$; meaning there is no noise (Fig3.a) and a noisy environment with an $\mathrm{SNR}_{\mathrm{dB}}$ of $40 \mathrm{~dB}$ (Fig3.b), a usual value in electrical systems.

Fig.3 displays the actual and estimated rotor position. Fig.4 shows the absolute value of the estimated rotor position error. We can clearly see the negative influence of the noise in the estimation performance. Of course increasing the voltage amplitude will improve the result but to what extent?

On the other hand, the injection voltage value should be kept to a minimum because it introduces additional losses. However, a very small, and therefore ideal, injection value would threaten the quality of the estimation due to the noise, as it has been pointed before. Therefore, a clear compromise exists in setting such value. Traditionally, such compromise has been solved with a trial and error process at the experimental stage. Rather than proposing a variation on, or an improvement of the well-known HF injection technique [1420], this paper establishes new criteria to conveniently set the injection voltage amplitude taking into account the noisy environment. Also, the contribution relies on the fact that such voltage amplitude value is discussed in a more analytical approach surpassing the experimental trial an error traditional methodology. The paper is organized as follows: in section III, the analytical model of the PMSM under high-frequency voltage excitation including the noise is established to derive the resulting injection currents. In section IV, the model is evaluated through intensive simulations and the results are compared to those obtained with the whole drive simulation. In the fifth section, we present experimental implementation of this HFI estimator and the comparison with simulation results. Finally a conclusion closes the paper.

\section{Dynamic ANAlytical HFI-PMSM Model}

For all injection methods to work, a minimum saliency level is needed. Injection techniques are more straightforward for salient machines such as interior PMSM than for Surface mount PMSM, which only possess a small saliency due to magnetic saturation caused by the permanent magnet. This makes the technique prone to interference from distorting effects such the converter non-linearities [23-25] in addition to spatial field non-linearities in the machine [6, 7].

When a high frequency voltage is applied to the machine windings, the resulting high frequency current signal contains the rotor position information. By demodulating those currents, the rotor position can therefore be estimated.

The analytical model includes the additional noise to the voltage supply and computes the resulting high frequency injected currents.

\section{A. Analytical Model of the PMSM with HFI}

The stator voltage model in the rotor reference frame for a PMSM is given by:

$$
\left[\begin{array}{l}
V_{d} \\
V_{q}
\end{array}\right]=\left[\begin{array}{cc}
R_{s} & 0 \\
0 & R_{s}
\end{array}\right]\left[\begin{array}{l}
i_{d} \\
i_{q}
\end{array}\right]+\left[\begin{array}{cc}
\rho & -w_{r} \\
w_{r} & \rho
\end{array}\right]\left[\begin{array}{l}
\Psi_{d} \\
\Psi_{q}
\end{array}\right]
$$

Where $\rho$ is a differential operator. The magnetic flux is given by:

$$
\left[\begin{array}{l}
\Psi_{d} \\
\Psi_{q}
\end{array}\right]=\left[\begin{array}{cc}
L_{d} & 0 \\
0 & L_{q}
\end{array}\right]\left[\begin{array}{l}
i_{d} \\
i_{q}
\end{array}\right]+\left[\begin{array}{l}
\psi_{m} \\
0
\end{array}\right]
$$

Transforming (2) into the stationary reference frame $\left(w_{r}=0\right)$ results in the following stator voltage equations:

$$
\left[\begin{array}{c}
V_{\alpha} \\
V_{\beta}
\end{array}\right]=\left[\begin{array}{cc}
R_{s} & 0 \\
0 & R_{s}
\end{array}\right]\left[\begin{array}{c}
i_{\alpha} \\
i_{\beta}
\end{array}\right]+\left[\begin{array}{cc}
w_{r} & 0 \\
0 & w_{r}
\end{array}\right]\left[\begin{array}{l}
\Psi_{\alpha} \\
\Psi_{\beta}
\end{array}\right]
$$

The high-frequency injection voltages with constant amplitude and angular frequency $\omega_{i}$ are described as follows [5, 21].
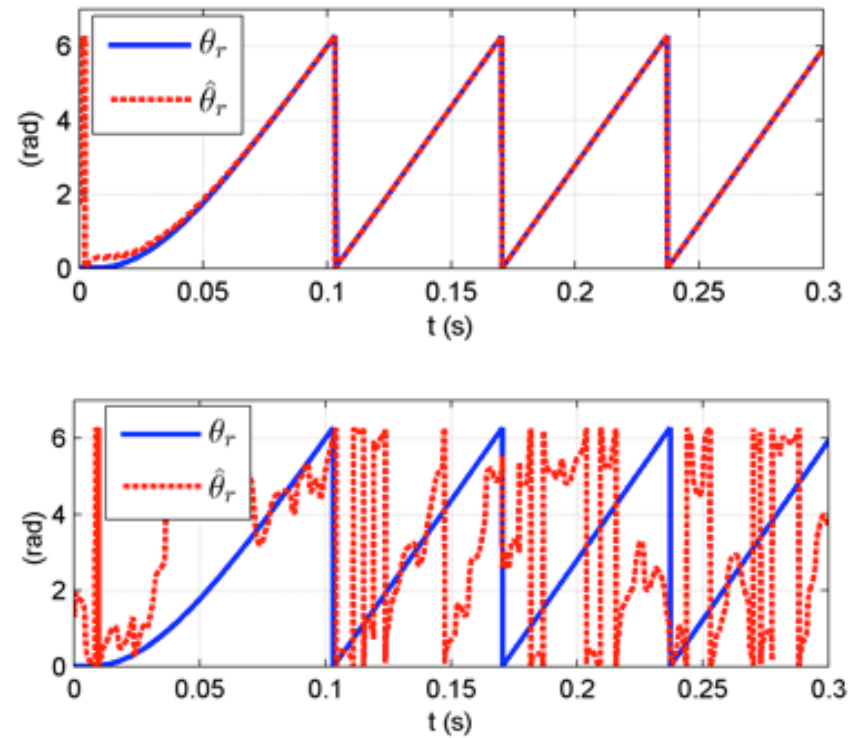

Fig.3. Actual and estimated rotor positions with the global model (in electrical radian) 


$$
\left[\begin{array}{c}
V_{\alpha i} \\
V_{\beta i}
\end{array}\right]=V_{s i}\left[\begin{array}{c}
-\sin \left(\omega_{i} t\right) \\
\cos \left(\omega_{i} t\right)
\end{array}\right]
$$

For high frequency signals the stator resistance and the effects of the permanent magnet flux linkages can be neglected. A PMSM has a small saliency mainly due to stator saturation from the main magnets.

After applying a band pass filter centered at the HFI frequency, the following currents are obtained $[19,21,22]$ :

$$
\begin{aligned}
& {\left[\begin{array}{l}
I_{i 0} \cos \left(\omega_{i} t\right)+I_{i 1} \cos \left(2 \theta_{r}-\omega_{i} t\right) \\
I_{i 0} \sin \left(\omega_{i} t\right)+I_{i 1} \sin \left(2 \theta_{r}-\omega_{i} t\right)
\end{array}\right]} \\
& I_{i 0}=\frac{V_{s i}\left(L_{q}+L_{d}\right)}{2 w_{i} L_{q} L_{d}} ; I_{i 1}=\frac{V_{s i}\left(L_{q}-L_{d}\right)}{2 w_{i} L_{q} L_{d}}
\end{aligned}
$$

In order to extract the angle information contained in the negative sequence component $I_{i l}$, the synchronous filter signal processing steps detailed in Fig. 2 have to be applied. By doing the Park transformation with a rotating frequency equal to minus the injected one $\left(-\omega_{\mathrm{i}} / 2 \pi\right)$, the novel currents are:

$$
\left[\begin{array}{l}
I_{i 0}+I_{i 1} \cos \left(2 \theta_{r}-2 \omega_{i} t\right) \\
I_{i 0}+I_{i 1} \sin \left(2 \theta_{r}-2 \omega_{i} t\right)
\end{array}\right]
$$

A high pass filter is then applied to (8) obtaining:

$$
\left[\begin{array}{c}
I_{i 1} \cos \left(2 \theta_{r}-2 \omega_{i} t\right) \\
I_{i 1} \sin \left(2 \theta_{r}-2 \omega_{i} t\right)
\end{array}\right]
$$

To move the angle information back to the fundamental reference frame the Park transform is applied with a rotating frequency equal to $\left(+2 \omega_{\mathrm{i}} / 2 \pi\right)$, and the information appears as follows:

$$
\left[\begin{array}{c}
I_{i 1} \cos \left(2 \theta_{r}\right) \\
I_{i 1} \sin \left(2 \theta_{r}\right)
\end{array}\right]
$$

Finally to estimate the electrical angle the arctangent function must be applied:

$$
2 \hat{\theta}_{r}=\tan ^{-1}\left(\frac{I_{i 1} \cos \left(2 \theta_{r}\right)}{I_{i 1} \sin \left(2 \theta_{r}\right)}\right)
$$

Depending on the quality of the estimation and the overall bandwidth an additional low pass filter may be applied, as Fig 2 illustrates.

\section{B. HFI Model for Position Estimation in Noisy Environment}

Now we assume that an AWGN (Additive White Gaussian Noise) is superimposed to the three phase voltages as follows:

$$
\left[\begin{array}{c}
V_{a n} \\
V_{b n} \\
V_{c n}
\end{array}\right]=V_{s i}\left[\begin{array}{c}
\cos \left(\omega_{i} t\right) \\
\cos \left(\omega_{i} t-\frac{2 \pi}{3}\right) \\
\cos \left(\omega_{i} t+\frac{2 \pi}{3}\right)
\end{array}\right]+\left[\begin{array}{c}
n_{1} \\
n_{2} \\
n_{3}
\end{array}\right]
$$

Where: $n_{1} \neq n_{2} \neq n_{3}$
After transforming the balanced high frequency voltage from the $(a, b, c)$ frame to the two-phase reference frame we obtain:

$$
\left[\begin{array}{c}
V_{\alpha i n} \\
V_{\beta i n}
\end{array}\right]=\left[\begin{array}{c}
-V_{s i} \sin \left(\omega_{i} t\right)+N_{\alpha} \\
V_{s i} \cos \left(\omega_{i} t\right)+N_{\beta}
\end{array}\right]
$$

Where: $N_{\alpha}=\frac{2}{3} n_{1}-\frac{n_{2}}{3}-\frac{n_{3}}{3} ; N_{\beta}=\frac{\sqrt{3}}{3} n_{2}-\frac{\sqrt{3}}{3} n_{3}$

Combining (6) and (12), the analytical model is derived to compute the resulting derivatives of the currents:

$$
\begin{aligned}
& \left\{\begin{array}{c}
\frac{d i_{\alpha i}}{d t}=-I_{i 0} \omega_{i} \sin \left(\omega_{i} t\right)+I_{i l} \omega_{i} \sin \left(2 \theta_{r}-\omega_{i} t\right) \\
\quad+L_{l}\left(N_{\alpha} \cos \left(2 \theta_{r}\right)+N_{\alpha} \sin \left(2 \theta_{r}\right)\right)+L_{2} N_{\alpha}
\end{array}\right. \\
& \begin{array}{r}
\frac{d i_{\beta} i}{d t}=I_{i 0} \omega_{i} \cos \left(\omega_{i} t\right)-I_{i l} \omega_{i} \cos \left(2 \theta_{r}-\omega_{i} t\right) \\
+L_{l}\left(N_{\beta} \sin \left(2 \theta_{r}\right)-N_{\beta} \cos \left(2 \theta_{r}\right)\right)+L_{2} N_{\beta}
\end{array} \\
& \text { Where: } \quad L_{1}=\frac{L_{q}-L_{d}}{2 L_{q} L_{d}} ; \quad L_{2}=\frac{L_{q}+L_{d}}{2 L_{q} L_{d}}
\end{aligned}
$$

In (13), with no noise $\left(N_{\alpha}=N_{\beta}=0\right)$, one can find the usual model of the HFI and demodulating the currents gives access to the rotor position. In (13), one can also notice that the noise clearly corrupts the rotor position estimation. Fig. 5 shows how the analytical model is used to evaluate the rotor position estimation.

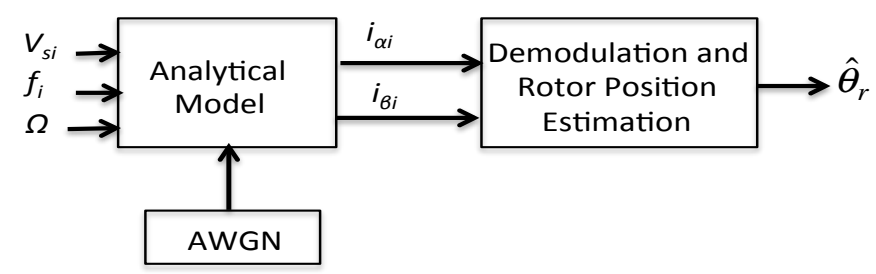

Fig.5. Estimation of the PMSM rotor position using the Analytical Model of the HFI in Noisy Environment.
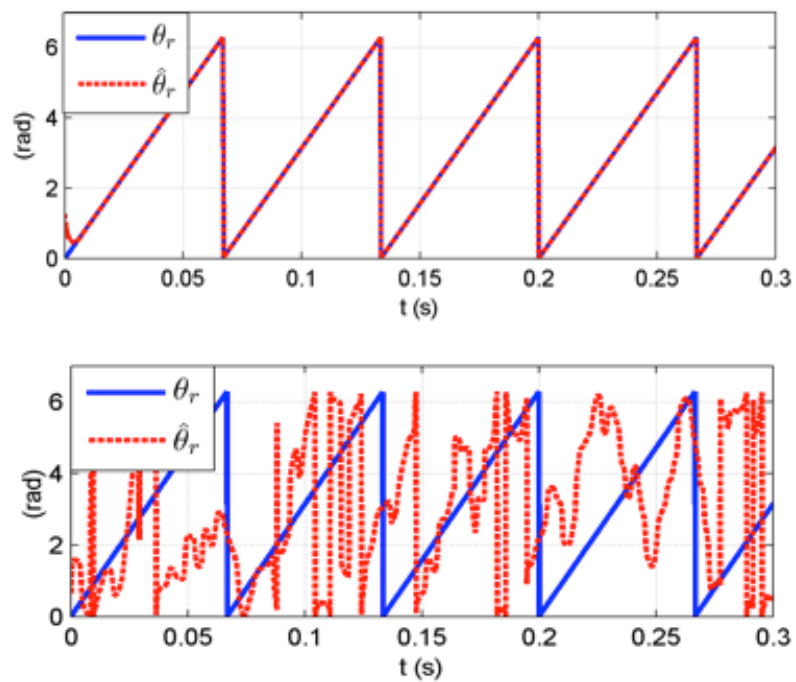

Fig.6. Actual and estimated rotor position with the analytical model (in electrical radian) 


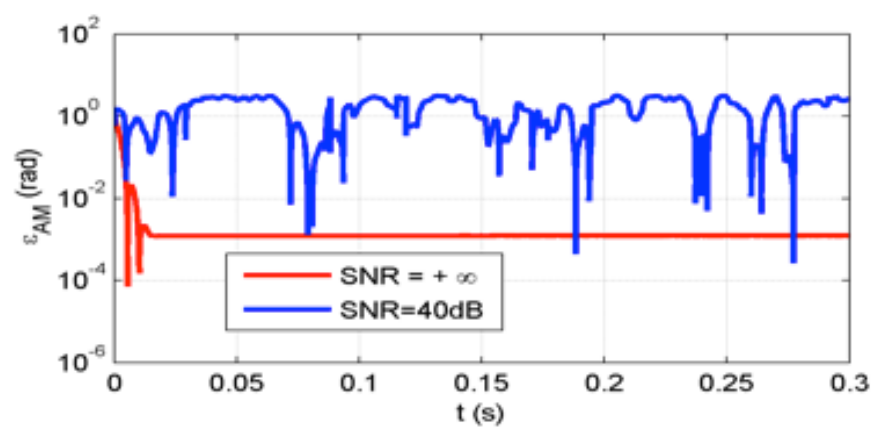

Fig.7. Rotor position errors with the analytical model (in electrical radian)

This is confirmed by the results displayed in Fig.6b. This analytical model is a useful tool to evaluate the impact of the noise on the rotor position estimation quality.

Fig.6 displays the actual and estimated rotor position with the analytical model. Fig.7 shows the absolute value of the estimated rotor position error in semi-log scale.

\section{Simulation Results}

\section{A. Analytical Model Results}

The simulations are performed with Matlab-Simulink ${ }^{\circledR}$.The parameters of the PMSM are listed in Table I.

The operating point is set in the low speed region $\left(\Omega<10 \% \Omega_{n}\right.$ ] at no load, where $\Omega_{n}$ is the nominal speed in $\mathrm{rad} / \mathrm{s}$.

The HFI signal voltage is set in the range of $\left[0,10 \% V_{m}\right]$, where $V_{m}=12 \mathrm{~V}$.

\section{TABLE I}

Surface Mount PMSM Characteristics

\begin{tabular}{c|c|c}
\hline Symbol & Definition & Value \\
\hline$P_{n}$ & Nominal power & $1.1 \mathrm{~kW}$ \\
\hline$\Omega_{n}$ & Nominal speed & $356 \mathrm{rad} / \mathrm{s}$ \\
\hline$T_{n}$ & Load torque & $3.2 \mathrm{Nm}$ \\
\hline$P$ & Pole pairs & 3 \\
\hline$I n$ & Nominal current & $5.9 \mathrm{~A}$ \\
\hline$R_{s}$ & Stator resistance & $1.65 \Omega$ \\
\hline$L_{d}$ & $d$ axis inductance & $3.510^{-3} \mathrm{H}$ \\
\hline$L_{q}$ & $q$ axis inductance & $4.510^{-3} \mathrm{H}$ \\
\hline$\Psi_{m}$ & Magnetic flux & $15410^{-3} \mathrm{~Wb}$ \\
\hline$f$ & Viscous friction & $50910^{-3} \mathrm{Nm} / \mathrm{rad}$ \\
\hline$J$ & Moment of inertia & $6.410^{-3} \mathrm{~kg} / \mathrm{m}^{2}$ \\
\hline
\end{tabular}

Fig. 8 shows the performances of the speed and position tracking obtained with the analytical model when the reference speed is changed from $(+10 \mathrm{rad} / \mathrm{s})$ to $(-10 \mathrm{rad} / \mathrm{s})$.

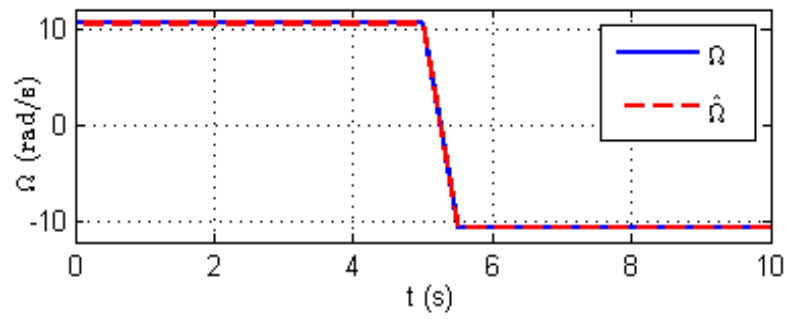

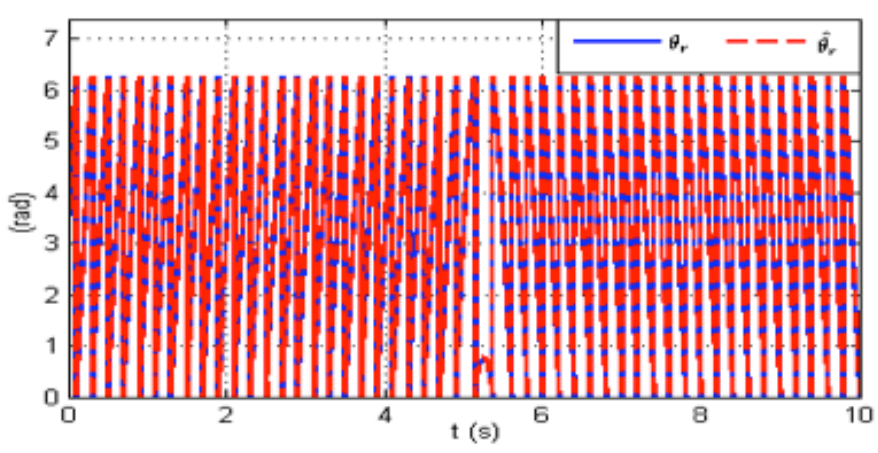

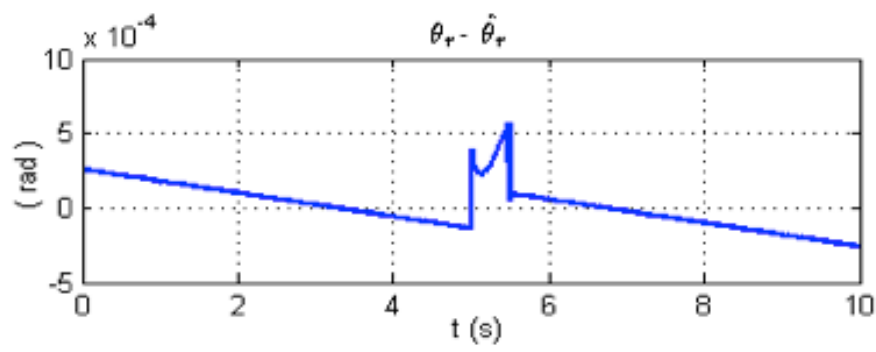

Fig.8. Simulation results with the analytical model during a speed reversal test.

\section{B. Comparison between Global and Analytical Models}

Figs. 9 and 10 show the influence of the voltage amplitude (expressed as a percentage of $V_{m}$ ) on the position error for different $\mathrm{SNR}_{\mathrm{dB}}$ levels with the analytical and the global model respectively.

The error between the actual and the estimated position is computed as follows:

$$
\varepsilon_{A M}=\varepsilon_{G M}=\left|\theta_{r}-\hat{\theta}_{r}\right|
$$

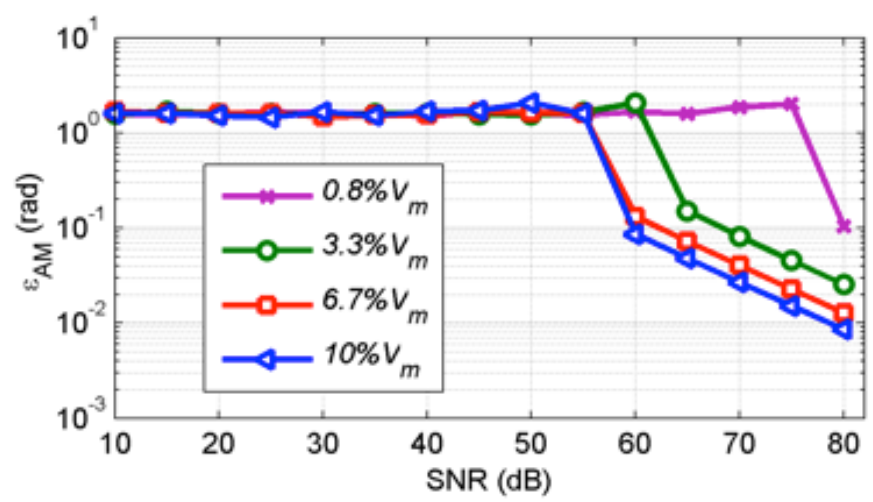

Fig.9.Effect on the position error signal obtained with the analytical model in noisy environment (in electrical radian).

Simulation results for both models show that the increase of the injected voltage amplitude in the noisy environment significantly improves the performance of the HFI for the rotor position estimation. The discrepancies of roughly (5dB) are due to the differences between the two models. Let's recall that the global model includes the speed and current control loops of the PMSM model while the analytical model is a straightforward relation of the resulting injected currents. 


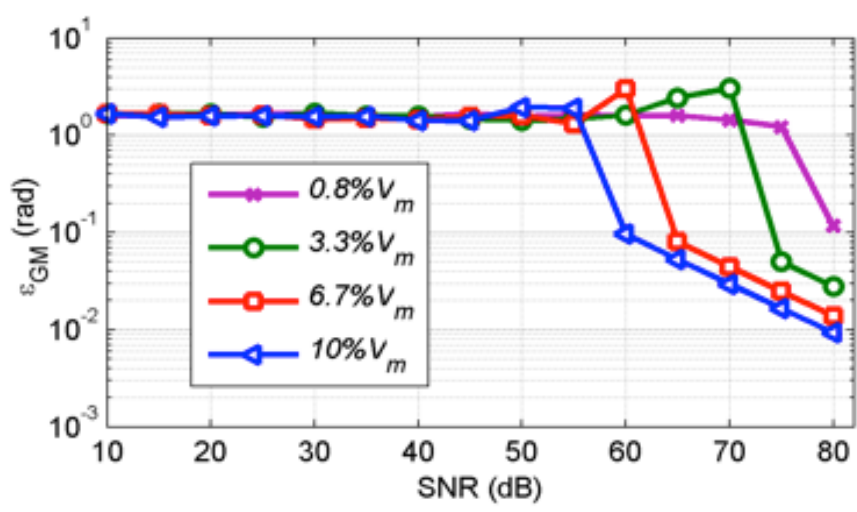

Fig.10.Effect of on the position error signal obtained with the global model in noisy environment (in electrical radian).

For both models, the error decreases significantly from around $\mathrm{SNR}_{\mathrm{dB}}=55 \mathrm{~dB}$ if the injected voltage amplitude is high enough $\left(6.7 \%\right.$ and $10 \%$ of $\left.V_{m}\right)$. It allows a better estimation of the rotor position. The differences between the two models for high SNR values is due to the numerical effects of the simulation in the global model that includes the vector control and the PMSM model. The main advantage of the analytical model is the short computation time compared to the global model. Therefore it can be used to evaluate quickly the efficacy of the voltage injection for rotor position estimation. The flowchart depicted in Fig.11 describes the proposed approach.

For a given speed range and injection frequency, the user specifies the SNR and the maximum acceptable rotor position estimation error (for his application and thanks to the analytical model, the injection voltage amplitude is set appropriately. One way to evaluate the $\mathrm{SNR}_{\mathrm{dB}}$ is described in Fig.12. The low pass (LPF) and high pass (HPF) filters are tuned so as to respectively include and reject the injected fundamental frequency (the maximum being $170 \mathrm{~Hz}$ in our application). The SNR is computed with (1) after the determination of the Power Spectral Density (PSD).

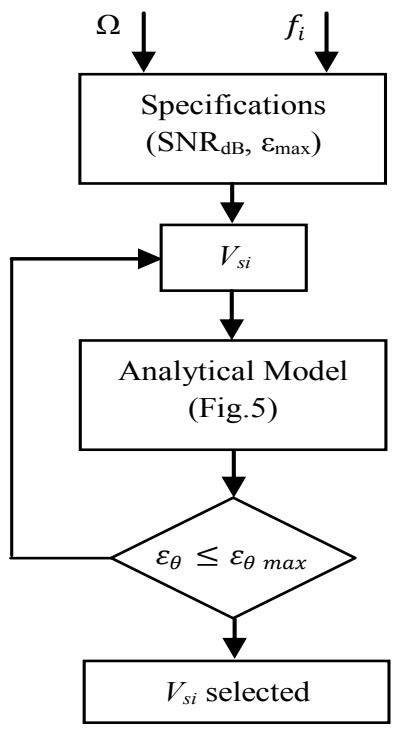

Fig.11. Flowchart of the injection voltage setting

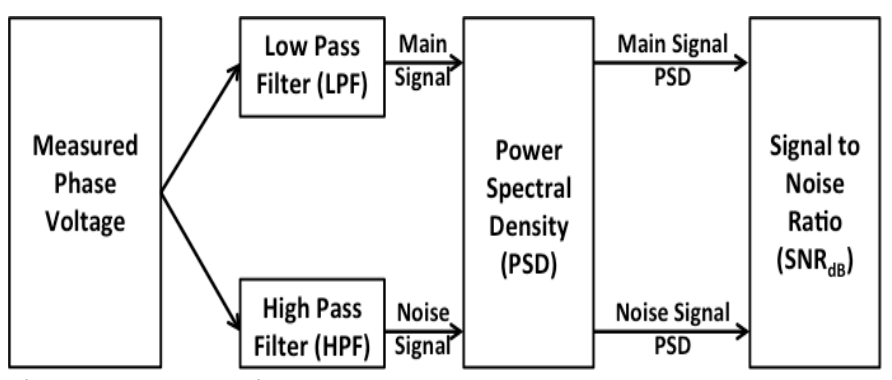

Fig.12. SNR computation process.

In the next section, the experimental validation of our approach is presented.

\section{EXPERIMENTAL RESULTS}

The nominal controller based on the standard vector control and the estimator HFI are implemented on a PMSM drive as displayed in fig. 13 with the parameters shown in Table I, using Matlab-Simulink ${ }^{\circledR}$ and downloaded in a dSpace ${ }^{\circledR} 1103$ board. The current control algorithm is carried out every $100 \mu \mathrm{s}$, and the speed control loop is carried out every $1 \mathrm{~ms}$.

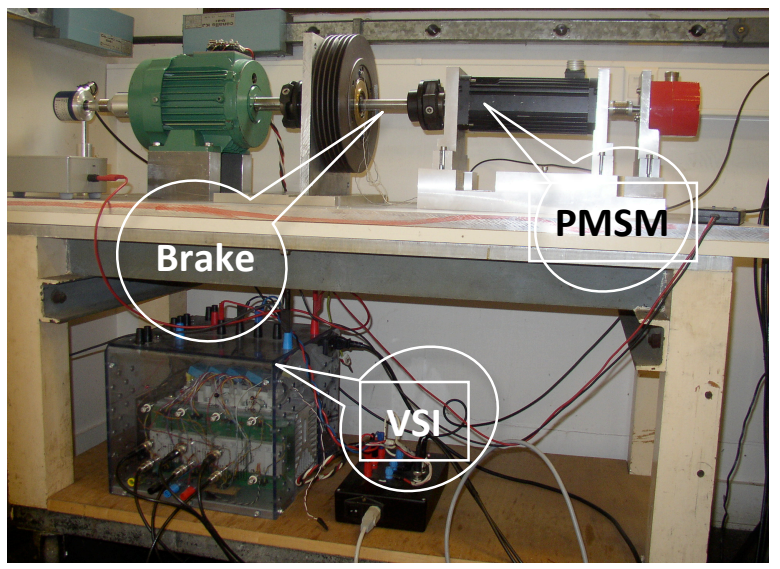

Fig.13. Laboratory test bed.

The inverter switching frequency is $20 \mathrm{kHz}$ and the DC bus voltage is set at $200 \mathrm{~V}$.

The operation point is set at no load with a mechanical speed of $31.4 \mathrm{rad} / \mathrm{s}$ (corresponding to $10 \%$ of the motor maximal speed).

The amplitude of the HFI voltage is set manually through the graphical user interface of Control Desk ${ }^{\circledR}$ and the measured and estimated rotor position are computed as shown in Fig.1.

The results are displayed in fig. 14 with different amplitudes of the voltage. We can notice clearly the improvement of the position estimation as the voltage increases.

For comparison purpose, considering $2 \mathrm{~s}$ of time duration, mean values and variances of the estimation errors for the analytical model, the global model and the experimental drive are displayed in Table II. 

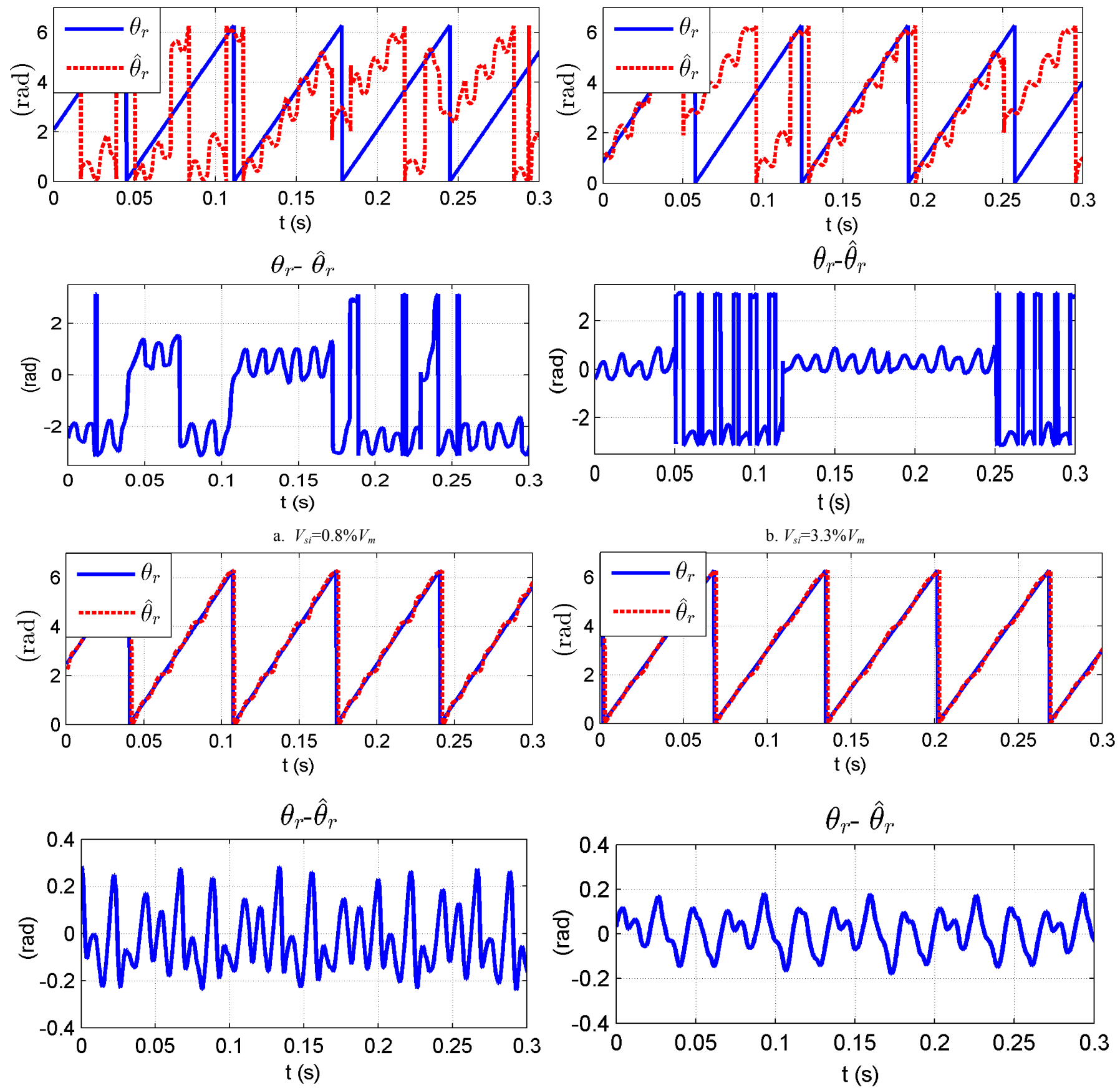

c. $\quad V_{s i}=6.7 \% V_{m}$

d. $V_{s i}=10 \% V_{m}$

Fig.14. Actual, estimated and errors rotor position under different voltages levels injection (all angles are in electrical radian)

TABLE II

Characteristics of the estimation errors

\begin{tabular}{l|c|c|c|c|c}
\hline $\begin{array}{l}V_{s i} \\
\left(\% V_{m}\right)\end{array}$ & & 0.8 & 3.3 & 6.7 & 10 \\
\hline \multirow{2}{*}{$\begin{array}{l}\text { Analytical } \\
\text { Model }\end{array}$} & $\mu$ & $14 \mathrm{e}-2$ & $5 \mathrm{e}-2$ & $-1 \mathrm{e}-3$ & $-1 \mathrm{e}-3$ \\
\cline { 2 - 6 } & $\sigma^{2}$ & 11.7 & 8.9 & $3 \mathrm{e}-4$ & $3 \mathrm{e}-4$ \\
\hline \multirow{2}{*}{$\begin{array}{l}\text { Global } \\
\text { Model }\end{array}$} & $\mu$ & $12 \mathrm{e}-2$ & $-6 \mathrm{e}-2$ & $-15 \mathrm{e}-4$ & $-4 \mathrm{e}-4$ \\
\cline { 2 - 6 } & $\sigma^{2}$ & 15 & 6.25 & $6 \mathrm{e}-4$ & $3 \mathrm{e}-5$ \\
\hline \multirow{2}{*}{ Experiment } & $\mu$ & $-94 \mathrm{e}-2$ & $-13 \mathrm{e}-2$ & $-7 \mathrm{e}-2$ & $-4 \mathrm{e}-2$ \\
\cline { 2 - 6 } & $\sigma^{2}$ & 7.64 & 5.21 & $7.9 \mathrm{e}-4$ & $3.9 \mathrm{e}-4$ \\
\hline
\end{tabular}

From these results, we can notice:

- All the values are in the same order of amplitude; therefore the analytical model is a relevant approach in setting the HFI voltage amplitude.

- The more the voltage increases; lower are the mean value and the variance of the estimation errors. 


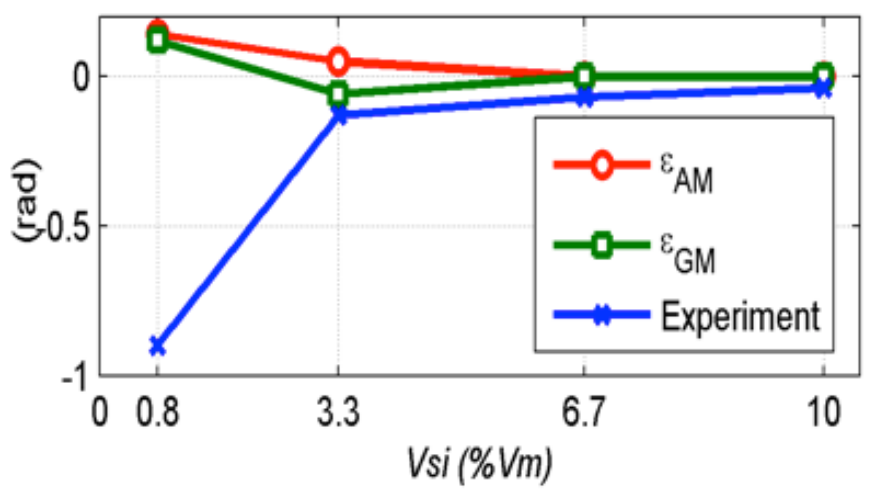

Fig.15. Mean value of position errors (in electrical radian) for $\mathrm{SNR}=62 \mathrm{~dB}$.

Fig.15 displays the estimation errors mean value. However, one can also notice that the injected voltage (from $6.7 \%$ to $10 \%)$ led to an improvement of the estimation at the detriment of higher injected currents and torque ripples. The consequence is the reduction of the efficiency despite a better

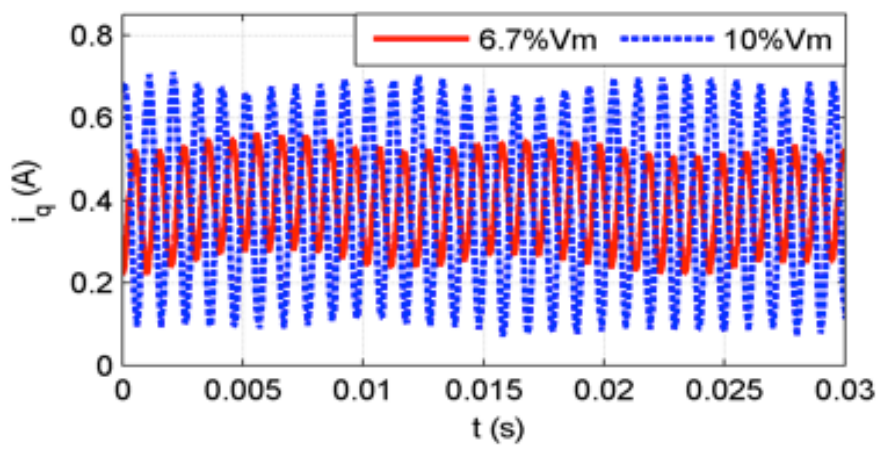

Fig.16. Stator torque current at $31.4 \mathrm{rad} / \mathrm{s}$.

position estimation accuracy. This is confirmed by the oscillation in the torque current as displayed in Fig.16.

A summary of its experimental mean values and variances are displayed in Table III.

TABLE III

Characteristics of the $i_{q}$ component

\begin{tabular}{l|l|l|l|l|l}
\hline $\begin{array}{l}V_{s i} \\
\left(\% V_{m}\right)\end{array}$ & & 0.8 & 3.3 & 6.7 & 10 \\
\hline \multirow{2}{*}{ Experiment } & $\mu$ & 0.37 & 0.37 & 0.38 & 0.38 \\
\cline { 2 - 6 } & $\sigma^{2}$ & $2.8 \mathrm{e}-7$ & $3.2 \mathrm{e}-6$ & $1.1 \mathrm{e}-4$ & $2 \mathrm{e}-3$ \\
\hline
\end{tabular}

However the speed estimation is still accurate with fewer ripples as it can be seen in Fig.17.

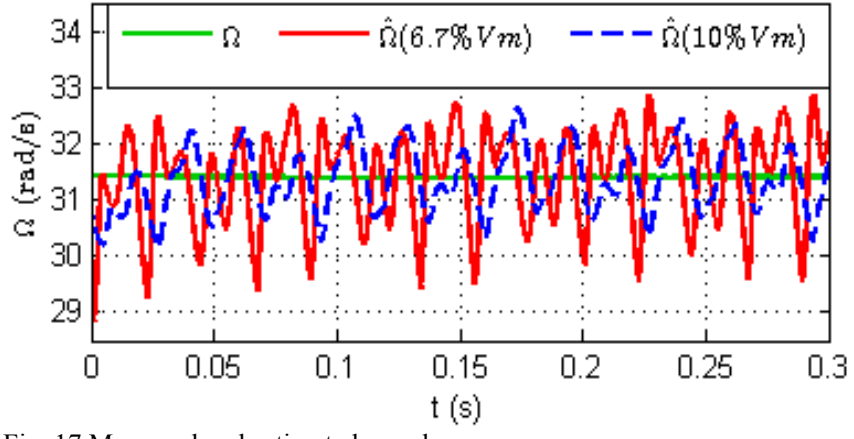

Fig. 17 Measured and estimated speeds

Looking at fig.18, one can notice that for the same position estimation error, the HFI voltage amplitude can be decreased as the speed increases from $1\left(0.33 \% \Omega_{n}\right)$ to $31.4 \mathrm{rad} / \mathrm{s}(10 \%$ $\left.\Omega_{n}\right)$.

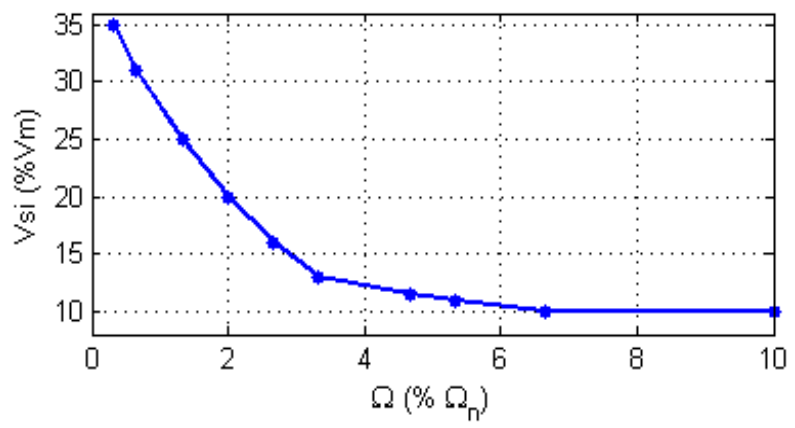

Fig.18. High Frequency Injection voltage amplitude

To improve the estimation of the HFI, it is necessary to evaluate the robustness against load torque variations and speed reversal.
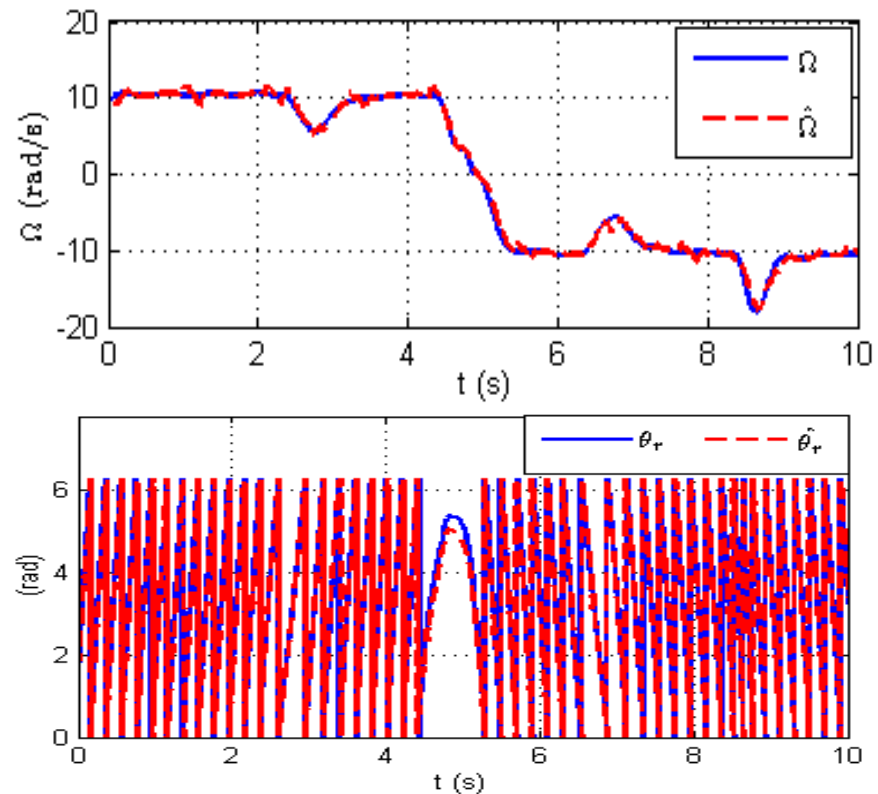

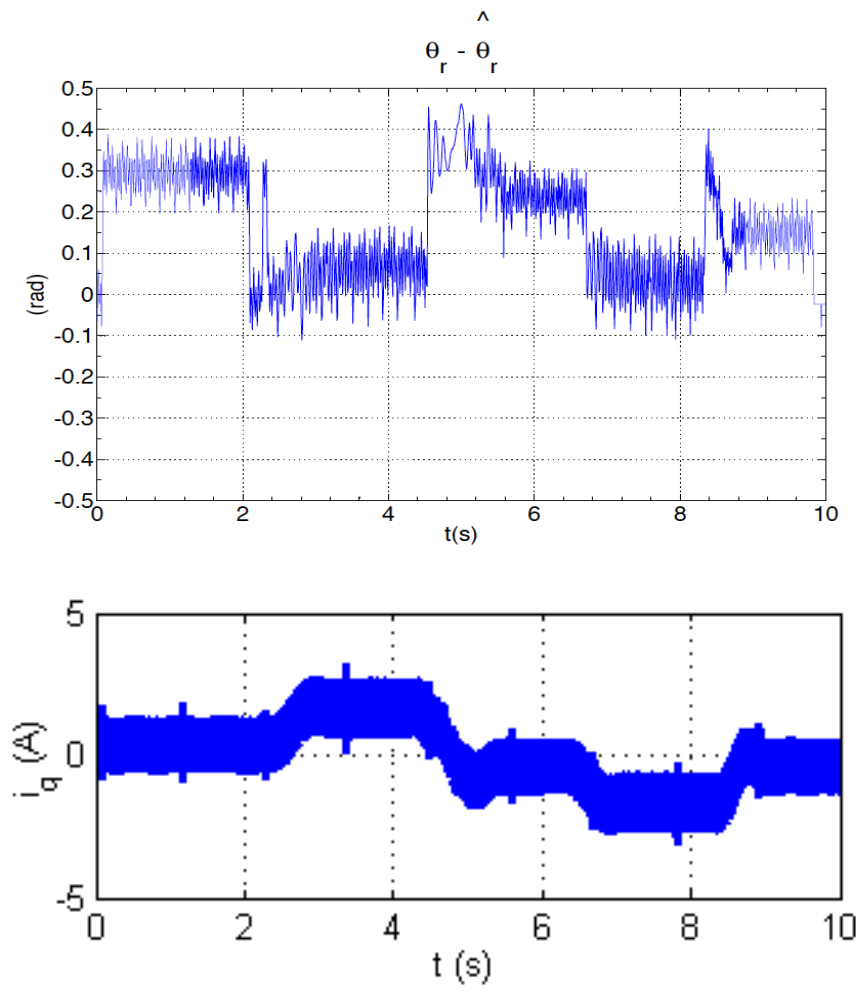

Fig.19. Experimental results during a speed reversal test under load torque.

Fig.19 displays the experimental results with a time varying speed reference from +10 to $-10 \mathrm{rad} / \mathrm{s}$ and a step resistive torque of $0.5 \mathrm{Nm}$ (produced by setting the powder brake current) applied in the time ranges $[2.3 \mathrm{~s}-4.5 \mathrm{~s}]$ and $[6.3 \mathrm{~s}-$ $8.3 \mathrm{~s}]$ is added to the friction torques. These results show the performances of the mechanical rotor speed and rotor electric position tracking capabilities of the HFI. The position error estimation varies in the \pm 0.3 electrical radian range (corresponding to \pm 0.1 radian for the mechanical angle), which is an acceptable error to further close the loop. However, it must be pointed that the load dependent error, which can be easily compensated for, has not been implemented in the present experimentation. This is why the error changes whenever there is a change of load.

\section{CONCLUSION}

In this paper, we have proposed a methodology to set efficiently the voltage amplitude of the high frequency injected signal in PMSM drive for rotor position estimation. The main contribution is the development of an analytical model including the voltage supply noise ratio to derive the resulting injection currents. This model allows determining the appropriate HFI voltage level for a given $\mathrm{SNR}_{\mathrm{dB}}$ and a required maximum position error. The overall improvement is a reduction of the resulting injection currents that lead to a better efficiency and a lower rate of torque ripples. The HFI scheme becomes more attractive for sensorless application or as a redundant position sensor in a fault tolerant strategy.

\section{REFERENCES}

[1] S. Mohammad. Widyan and Rolf E. Hanitsch, " High-power density radial-flux permanent-magnet sinusoidal three-phase three-slot four-pole electrical generator," Int. J. Electr Power Energy Syst 2012; 43:1221-7.

[2] Q. Gao, S. Shen, and T. Wang, "A novel drive strategy for PMSM compressor," in Conf. Rec., IEEEICECE, June 2010, pp. 319 - 3195.

[3] S. Yu, Z. Yang, S. Wang and K. Zheng, "Sensorless adaptive backstepping speed tracking control of uncertain permanent magnet synchronous motors," in Conf. Rec., IEEE-ISCAA, June 2010, pp. 11311135.

[4] Z. Peroutka, K. Zeman, F. Krus, and F. Kosten, "New generation of trams with gearless wheel PMSM drives: From simple diagnostics to sensorless control," in IEEE Conf. Rec., 14th International Power Electronics and Motion Control Conference EPE-PEMC, September 2010, pp. 31-36.

[5] J. Holtz, "Sensorless Control of Induction Machines; With or Without Signal Injection?," Industrial Electronics, IEEE Transactions on, vol. 53, pp. 7-30, 2006.

[6] P. P. Acarnley and J. F. Watson, "Review of position-sensorless operation of brushless permanent-magnet machines," Industrial Electronics, IEEE Transactions on, vol. 53, pp. 352-362, 2006.

[7] M. Pacas, "Sensorless Drives in Industrial Applications," Industrial Electronics Magazine, IEEE, vol. 5, pp. 16-23, 2011.

[8] F. Zidani, D. Diallo, and M. E. H. Benbouzid, "A fuzzy-based approach for the diagnosis of fault modes in a voltage-fed PWM inverter induction motor drive," IEEE Trans. Ind. Electronics, Vol. 55, n² 2, pp. 586-593, Feb. 2008.

[9] F-J. Lin, Y.-C., J.-M. Chen, C.-M. Yeh, "Sensorless IPMSM Drive System Using Saliency Back-EMF-Based Intelligent Torque Observer With MTPA Control, “ IEEE Transactions on Industrial Informatics Vol. 10, Issue: 2, 2014, Page(s): 1226 - 1241

[10] J. Holland, "Adaptation in Natural and Artificial Systems," MIT Press, 1975.

[11] Y. Liang, Yongdong Li, "Sensorless control of PM synchronous motors based on MRAS method and initial position estimation," 6th ICEMS, 911 Nov. 2003, Vol.1, pp. 96-99.

[12] S. Bolognani, L. Tubiana, M. Zigliotto, "EKF-based sensorless IPM synchronous motor drive for flux-weakening applications," IEEE Transactions on Industry Applications, vol.39, Issue 3, May-June 2003, pp.768-775.

[13] Li. Changsheng; M. Melbuluk, "A sliding mode observer for sensorless control of permanent magnet synchronous motors," Conference Record of the 36th IAS Annual Meeting. Sept./Oct. 2001, Vol.2, pp. 1273-1278.

[14] A. Arias, O.Carlos, Z. Jordi,J.Espina, J. Pou,"Hybrid sensorless permanent magnet synchronous machine four quadrant drive based on direct matrix converter," Electrical Power and Energy Systems 45, 7886, 2013.

[15] P. L. Jansen and R. D. Lorenz,"Transducerless position and velocity estimation in induction and salient AC machines," IEEE Trans. Ind. Appl., vol.31, no.2, pp. 240-247, Mar./Apr.1995.

[16] J. Cilia, G. M. Asher, K. J. Bradley, and M. Sumner, "Sensorless position detection for vector-controlled induction motor drives using an asymmetric outer-section cage," IEEE Trans. Ind. Appl., vol. 33, no. 5, pp. 1162-1169, Sep./Oct. 1997.

[17] N. Teske, G. M. Asher, M. Sumner, and K. J. Bradley, "Encoderless position estimation for symmetric cage induction machines under loaded conditions", IEEE Trans. Ind. Appl., vol. 37, no. 6, pp. 1793-1800, Nov./Dec. 2001.

[18] O. Mansouri-Toudert, H. Zeroug, F. Auger, A. Chibah, "Improved rotor position estimation of salient-pole PMSM using high frequency carrier signal injection," IEEE International Conference on Mechatronics (ICM), Vicenza, pp.761 - 767, Feb. 27-Mar.1, 2013.

[19] A. Arias, C. Silva, G.M. Asher, JC. Clare, P.W.Wheeler, " Use of a matrix converter to enhance the sensorless control of a surface-mount permanent-magnet $\mathrm{AC}$ motor at zero and low frequency," IEEE Transactions and Electronics 53: 440-9,2006.

[20] S. Damkhi, M.S.Nait Said and N. Nait Said,"Slotting effects and high frequency signal injection for induction machine rotor speed estimation," International Conference and Exposition on Electrical and Power Engineering, Iasi, Romania, 25-27 October, 2012.

[21] C. Silva, G. M. Asher, M. Sumner, "Hybrid Rotor Position Observer for Wide Speed-Range Sensorless PM Motor Drives Including Zero Speed", Industrial Electronics, IEEE Transactions on, vol. 53, pp. 373-378, 2006 
[22] M.W. Degner, R.D. Lorenz, "Using Multiple Saliencies of the Estimation of flux, Position, and Velocity in AC Machines," IEEE Trans. Ind. Appl., Vol. 34, No. 5, Sept./Oct., pp. 1097-1104, 1998.

[23] P. Yongsoon, S. Seung-Ki, "A Novel Method Utilizing Trapezoidal Voltage to Compensate for Inverter Nonlinearity," Power Electronics, IEEE Transactions on, vol. 27, pp. 4837-4846, 2012.

[24] P. Yongsoon, S. Seung-Ki, "Implementation Schemes to Compensate for Inverter Nonlinearity Based on Trapezoidal Voltage," Industry Applications, IEEE Transactions on, vol. 50, pp. 1066-1073, 2014.

[25] P. Yongsoon S. Seung-Ki, "Sensorless Control Method for PMSM Based on Frequency-Adaptive Disturbance Observer," Emerging and Selected Topics in Power Electronics, IEEE Journal of, vol. 2, pp. 143151,2014

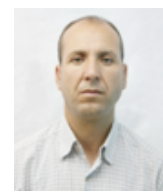

Slimane Medjmadj received the engineer and Magister degrees in Electrotechnique from the, University of Ferhat Abbas, Setif, Algeria, in 1996 and 2005, respectively. He is an Assistant Professor at the Mohammed El Bachir El Ibrahimi University, Bordj Bou Arréridj, Algeria in the Department of Electromecanique, and a member of the laboratory of Control (LAS), University of Setif (Algeria). His main research interests are diagnosis and fault tolerant control of electric drives. He's currently working toward a $\mathrm{PhD}$ at the Univ. of Setif.

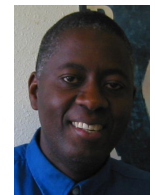

Demba Diallo (SM'05) received the M.Sc. and Ph.D. degrees both in Electrical and Computer Engineering, from the National Polytechnic Institute of Grenoble, France, in 1990 and 1993 respectively. Currently he is with the Laboratoire de Génie Electrique de Paris. He's head of the Design, Control and Diagnosis team. His area of research includes advanced control techniques and diagnosis of AC drives, design of electric powertrains and autonomous systems. He is Editor of the IEEE TRANSACTIONS ON VEHICULAR TECHNOLOGY.

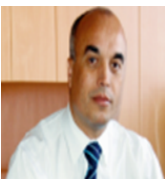

Mohammed Mostefai was born on April 1965, in B.B.A, Algeria. He received his M.Sc in electrical engineering in 1988 from the University of Setif, Algeria, and the $\mathrm{PhD}$ in Control and Software Engineering in 1994 from the University of Lille, France. He is now a full professor at the University of Setif. He has held several scientific and administrative responsibilities, first as president of the scientific committee, then as director of the Laboratory of Control (LAS) and finally as vice president for research at the University of Setif since February 2006. His research interests include study, modeling, analysis and control of industrial systems. The mainly covered applications are production systems, ranging from electro-energy systems (electric machines and networks) up to large automated manufacturing systems.

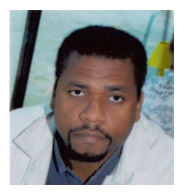

Claude Delpha (M'08) is an Associate Professor at the Univ. Paris-Sud, France, graduated in Electrical and Signal Processing Engineering. He obtains his Ph.D. from the Univ. of Metz in the field of signal processing for smart systems. Since 2001, he is with the Laboratoire des Signaux et Systèmes. He works in the field of signal processing for security and system monitoring (multimedia and smart systems). His main areas of interests are Multidimensional Signal Processing, Data hiding (Watermarking, Steganography), Pattern Recognition, Fault Detection and Diagnosis (incipient and intermittent).

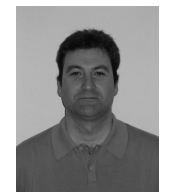

Antoni Arias (M'03) received the BEng degree in electrical engineering, MEng and $\mathrm{PhD}$ degrees in control and electronic engineering from the Universitat Politècnica de Catalunya (UPC), Catalonia, Spain, in 1993, 1997 and 2001 respectively. From 1992 to 1995 he worked at SADECT S.A., a local industrial electronics company. Since 1996 he has been a Lecturer at the UPC where he was appointed as an Associate Professor in 2002. In 1999 he was a visiting research assistant and part time lecturer at the University of Glamorgan, UK. In 2003 and 2004 he joined as a Visiting Fellow the Power Electronics, Machines and Control Group at the University of Nottingham, UK. In 2011 and 2012 he was at the Laboratoire de Génie Electrique de Paris as Invited Associate Professor. His research interests include sensorless variable-speed drive systems, power electronics converters and control strategies 